\title{
Synthesis of Geopolymers Using Local Resources for Construction and Water Purification
}

\author{
Arwa Hamaideh1, Bassam Al-Qarallah2, Moshrik R. Hamdi'3 , Saida Ali Abu Mallouh4, \\ Juma'a Khalil Al-Kafawein ${ }^{5}$, Mazen Alshaaer6,7 \\ ${ }^{1}$ Center of Water, Energy and Environment, The University of Jordan, Amman, Jordan \\ ${ }^{2}$ Horticulture and Crop Science Department, The University of Jordan, Amman, Jordan \\ ${ }^{3}$ Engicon, Amman, Jordan \\ ${ }^{4}$ Hamdi Mango Center for Scientific Research, The University of Jordan, Amman, Jordan \\ ${ }^{5}$ Department of Chemistry, King Faisal University, Al-Ahsa, KSA \\ ${ }^{6}$ Deanship of Academic Research, The University of Jordan, Amman, Jordan \\ ${ }^{7}$ Department of Physics, Salman Bin Abdulaziz University, Al-Kharj, KSA \\ Email: ${ }^{*}$ bassam702000@yahoo.com
}

Received 10 March 2014; revised 5 April 2014; accepted 19 April 2014

Copyright (C) 2014 by authors and Scientific Research Publishing Inc.

This work is licensed under the Creative Commons Attribution International License (CC BY).

http://creativecommons.org/licenses/by/4.0/

(c) (i) Open Access

\section{Abstract}

Large deposits of impure kaolins exist in Jordan and many parts of the world; geoplymers can reduce environmental impacts and have multi-application in many fields, such as water purification, waste treatment, fire proof construction, etc. The aim of this research is to investigate the use of alkali activated zeolitic tuff and low purity metakaolin as precursors for the production of functional geoplymers exhibiting proper mechanical properties and high potential for water storage and decontamination of polluted solutions. The results confirmed that this type of geopolymers showed superior mechanical characteristics and higher adsorption capacity towards heavy metals such as $\mathrm{Cu}$ (II) ions, which was similar to natural zeolite. X-ray diffraction analysis showed that phillipsite, a major zeolite mineral, disappeared upon geopolymerization, while scanning electron microscopy analysis showed that geopolymers exhibit a porous matrix of nano-particles. The geopolymers have also displayed high compressive strength and tensile bending strength of about 7.8 MPa and 45 MPa respectively, compared to reference geopolymers. This functional-geopolymers indicate that they are efficient, cost effective and have a potential for number of applications including construction, water storage and wastewater treatment.

\footnotetext{
${ }^{*}$ Corresponding author.
} 


\title{
Keywords
}

\author{
Geopolymer, Zeolitic Tuff, Metakaolin, Water Purification, Construction Material, Heavy Metals, \\ Jordan
}

\section{Introduction}

Geopolymers have drawn attention because of their great mechanical characteristics. It has been observed that through chemical polymerization reactions, aluminosilicates such as clays could be hardened and transformed into aluminosilicate polymers, also known as geopolymers, which are potential construction materials [1] [2]. Geopolymers consist of an amorphous, three-dimensional structure resulting from the polymerization of aluminosilicate monomers in an alkaline solution [3], aluminosilicate monomers in an alkaline solution [3].

The exact mechanism of geopolymerization is not known precisely until now. There is a good probability for $\mathrm{Na}^{+}$ions released from Na-alkali solution to replace hydrogen ions on the broken edges of the clay. As a result of this ion exchange, repulsion between the $\mathrm{Na}^{+}$ions will transform the two-dimensional phyllosilicates sheets into three-dimensional framework of tectosilicates [4]. Davidovits [5] has proposed a reaction pathway for geopolymerization involving polycondensation of hypothetical monomers, i.e. orthosialate ions [4]. Davidovits [5] has proposed a reaction pathway for geopolymerization involving polycondensation of hypothetical monomers, i.e. orthosialate ions. As a result of these reactions, solid, hard, and stable materials similar to hydroxysodalite, feldspathoid, or zeolite are formed [2]. When aluminum is four coordinated coordinated to oxygen atoms, a negative charge is created and therefore the presence of cations, such as $\mathrm{Na}^{+}$, is essential to balance electric charge in the geopolymeric matrix (hydroxysodalite). Hydroxysodalite, which maybe amorphous or microcrystalline, consists of $\mathrm{SiO}_{4}$ and $\mathrm{AlO}_{4}$ tetrahedra linked alternately by sharing all the oxygen atoms [6]. Positive ions $\left(\mathrm{Na}^{+}\right.$, $\mathrm{K}^{+}, \mathrm{Li}^{+}, \mathrm{Ca}^{2+}, \mathrm{Ba}^{2+}, \mathrm{NH}_{4}^{+}$, and $\mathrm{H}_{3} \mathrm{O}^{+}$) need be present in the framework cavities to balance the negative charge of $\mathrm{Al}$ in the fourfold coordination.

Little work was found in the published literature on the adsorption potential of geopolymers. Li et al. [7] studied the adsorption of methylene blue (MB) dye onto geopolymeric adsorbent based on fly ash. The synthesized geopolymer exhibited much higher adsorption capacity towards MB than fly ash itself. Wang et al. [8] prepared an amorphous aluminosilicate geopolymer through solid-state conversion of fly ash. The synthesized geopolymer was also found to have higher adsorption capacity towards $\mathrm{Cu}^{2+}$ ion $(92 \mathrm{mg} \mathrm{Cu} / \mathrm{g}$ adsorbent) than the fly ash itself $(0.1 \mathrm{mg} \mathrm{Cu} / \mathrm{g}$ adsorbent).

In order to combat large-scale pollution in many parts of the world caused by micropollutants, low cost materials with suitable mechanical properties and high adsorption capacity are required [9]. Geopolymers produced from local resources are considered as candidate materials for this purpose. They may be also used for the construction of water storage or transport facilities (e.g. pools, dams, channels) and as liners in landfills to improve leachates quality and minimize thus the risk for groundwater and soil contamination [10] [11].

This research focuses on preparation and evaluation of functional metakaolin-zeolitic tuff geopolymers using local resources from Jordan, in terms of microstructure, mechanical properties and potential for wastewater purification. Zeolitic tuff is a potential candidate material due to its availability and high adsorption capacity. The adsorption potential of the produced geopolymers towards $\mathrm{Cu}^{2+}$ ions is investigated.

\section{Materials and Methods}

Materials: The geopolymers were synthesized using low purity metakaolin, natural zeolitic tuff (JZ), and alkaline activators, namely sodium silicate $\left(\mathrm{Na}_{2} \mathrm{SiO}_{3}\right)$ and sodium hydroxide (Merck, Germany). The zeolitic tuff was from North-East Jordan deposits (Aritayn area) located around $50 \mathrm{~km}$ to the east from Amman, the capital. The mineral composition of this tuff belongs mainly to phillipsite type of zeolites [1] [11]. Table 1 shows the chemical composition of kaolinite and zeolitic tuff. JZ was pulverized, sieved through $450 \mu \mathrm{m}$ sieve, and exhibited a median grain size $\left(\mathrm{d}_{50}\right)$ of $70 \mu \mathrm{m}$. Jordanian kaolin with a purity of $60 \%$ [1] was from El-Hiswa deposit, which is located in the southern of Jordan about $45 \mathrm{~km}$ to the east of Al-Quweira town [12]. The elevation of the upper surface deposit ranges between 850 and $950 \mathrm{~m}$ above sea level. Thirty-two individual samples were collected from different $8 \mathrm{~m}$ of the upper layers of an outcrop, weighing in total $32 \mathrm{~kg}$. 
Table 1. Chemical composition of kaolinite (JK), and zeolitic tuff (JZ) [1].

\begin{tabular}{cccccccccccccc}
\hline & $\begin{array}{c}\mathrm{SiO}_{2} \\
\%\end{array}$ & $\begin{array}{c}\mathrm{TiO}_{2} \\
\%\end{array}$ & $\begin{array}{c}\mathrm{Al}_{2} \mathrm{O}_{3} \\
\%\end{array}$ & $\begin{array}{c}\mathrm{Fe}_{2} \mathrm{O}_{3} \\
\%\end{array}$ & $\begin{array}{c}\mathrm{MnO} \\
\%\end{array}$ & $\begin{array}{c}\mathrm{MgO} \\
\%\end{array}$ & $\begin{array}{c}\mathrm{CaO} \\
\%\end{array}$ & $\begin{array}{c}\mathrm{Na}_{2} \mathrm{O} \\
\%\end{array}$ & $\begin{array}{c}\mathrm{K}_{2} \mathrm{O} \\
\%\end{array}$ & $\begin{array}{c}\mathrm{P}_{2} \mathrm{O}_{5} \\
\%\end{array}$ & $\begin{array}{c}\mathrm{SO}_{3} \\
\%\end{array}$ & $\begin{array}{c}\mathrm{Cl} \\
\%\end{array}$ & $\begin{array}{c}\text { L.O.I. } \\
\%\end{array}$ \\
\hline $\mathrm{JK}$ & 48.80 & 0.86 & 25.10 & 7.50 & 0.01 & 0.21 & 0.68 & 0.21 & 1.40 & 0.16 & 2.93 & 0.10 & 12.00 \\
$\mathrm{JZ}$ & 38.30 & 3.12 & 11.2 & 13.10 & 0.180 & 10.30 & 7.39 & 1.96 & 1.09 & 0.41 & 0.10 & 0.17 & 12.60 \\
\hline
\end{tabular}

Slopes range between $1 \%$ and $5 \%$ and soils are highly calcareous, shallow on higher slopes, deeper on lower slopes and on gradients of less than $2 \%$. Soil texture is generally silty clay soil that show poor physical structure with relatively good fertility status. Soil surface is prone to crusting, erosion and water runoff where terminal rates of infiltration rate range $3-14 \mathrm{~mm} / \mathrm{h}$ [12]. Soil is generally susceptible to dispersion and capping which leads to very high proportions of runoff. Rainfall events of less than $5 \mathrm{~mm}$ can cause noticeable runoff flows. Rainfall is irregular and unpredictable occurs in the form of short, intensive storms between November and May, with a long-term average of less than $200 \mathrm{~mm}$ per annum. Only a small quantity of rain is retained by soil surfaces and most is lost either through direct evaporation from the surface or through runoff into gullies.

Production of geopolymers: The variables considered to investigate the alkaline activation process were: $\mathrm{SiO}_{2}$ (in sodium silicate solution) $/ \mathrm{Al}_{2} \mathrm{O}_{3}$ (in metakaolin) molar ratio of 1 , and $\mathrm{Na}_{2} \mathrm{O}$ (in sodium silicate and $\mathrm{NaOH}$ solutions) $/ \mathrm{Al}_{2} \mathrm{O}_{3}$ (in metakaolin) molar ratio of 1 . The $\mathrm{H}_{2} \mathrm{O} / \mathrm{Na}_{2} \mathrm{O}$ molar ratio was 16 . The weight ratio of zeolitic tuff to metakaolin is 0.6 . The aqueous solution with Stoichiometric amount of $\mathrm{Na}_{2} \mathrm{SiO}_{3}, \mathrm{NaOH}$ and $\mathrm{H}_{2} \mathrm{O}$ were mechanically mixed for $1 \mathrm{~min}$. The zeolitic tuff and metakaolin were dry mixed first and then the sodium hydroxide and sodium silicate solutions were added. All reagents were mixed for 15 minutes. The final pulp from each series was poured into three rectangular molds $(12 \mathrm{~cm} \times 2 \mathrm{~cm} \times 4 \mathrm{~cm}$ each). The molded specimens were cured in a ventilated oven at $40^{\circ} \mathrm{C}$ for $24 \mathrm{~h}$. After curing, specimens were removed from the molds and cooled at room temperature. The specimens were subjected to three point bending, and compression tests. In addition, nine discs $(2 \mathrm{~cm} \times 2 \mathrm{~cm} \times 1 \mathrm{~cm})$ were prepared from each mixture, to carry out mineralogical studies using Xray diffraction (XRD), and scanning electron microscopy (SEM) as well as to assess the adsorption capacity of the produced geopolymers.

Mineralogical analyses: XRD analyses were carried out on powdered samples of geopolymers to identify the dominant crystalline and potentially newly formed phases. The XRD patterns were obtained from $4^{\circ}$ to $40^{\circ} 2 \theta$ at a scan rate of $2 \% \mathrm{~min}$.

Morphology of the specimens was also studied with an Inspect F50 scanning electron microscope (Japan). The samples were pre-coated with platinum under an argon atmosphere.

Geopolymer properties: Three specimens $(10 \mathrm{~cm} \times 2 \mathrm{~cm} \times 4 \mathrm{~cm}$ each $)$ were tested for the three point bending strength under ambient conditions. The standard formula for strength in 3-pt bending of a specimen is used:

$$
\sigma=3 \mathrm{PL} / 2 \mathrm{bd}^{2}
$$

Here $\mathrm{P}$ is equal to the failure load, $\mathrm{L}$ is the support span, $\mathrm{d}$ is the sample height, and $\mathrm{b}$ is the sample width. The specimen's dimensions are: height $=20 \mathrm{~mm}$, width $=40 \mathrm{~mm}$ and length $100 \mathrm{~mm}$, the distance between the supports is $80 \mathrm{~mm}$ and the speed of the machine head during testing is $0.1 \mathrm{~mm} / \mathrm{minute}$. The compression tests were performed on three specimens with dimensions of $(2 \mathrm{~cm} \times 2 \mathrm{~cm} \times 4 \mathrm{~cm}$ of each. All tests were carried out in two replicates. The speed of the machine head during testing is $2 \mathrm{~mm} / \mathrm{minute}$. Compressive strength is obtained by dividing the failure load by the cross section area.

In order to assess the adsorption potential of the produced geopolymers, a group of geopolymeric discs from each composition immersed, and washed once everyday with distilled water for 4 days. The aim of this procedure is to remove the residual water-soluble salts from the geopolymers. Discs were immersed in standard solution $(250 \mathrm{mg} / \mathrm{L})$ of cupric acetate $\left(98 \%\right.$, Hopkin and Williams) in $0.1 \mathrm{M} \mathrm{NaClO}_{4}$ solution $(98)$ at $\mathrm{pH}=3(\mathrm{pH}$ adjusted using $\mathrm{NaOH} / \mathrm{HClO}_{4}$ ). Ten milliliter samples from each solution were withdrawn after $24 \mathrm{~h}$ of shaking, filtered through microfilters $\left(0.45 \mu \mathrm{m}\right.$ Nylon), and centrifuged prior to the determination of $\mathrm{Cu}^{2+}$ concentration using atomic absorption spectrometer (Spectroscan-80DV-Germany).

\section{Results and Discussion}

Micro structural characteristics: Figure 1 shows the XRD patterns of kaolin, zeolitic tuff and the geopolymers produced. The results show that kaolin contains mainly kaolinite and Quartz. Zeolitic tuff contains main- 
lyphillipsite as well as calcite, and kaolinite.

During metakaolin-alkali geopolymerization phillipsite disappeared due to dissolution in alkaline geopolymerisation environment as shown in the XRD pattern of the geopolymer. The high XRD background seen between $20^{\circ}$ to $40^{\circ}$ indicates the presence of amorphous phases [13]. The microstructure of geopolymers, presented as a SEM image Figure 2(a) and Figure 2(b), shows the coexistence of geopolymer gel, amorphous phase of residual zeolitic tuff (A), and partially unreacted metakaolin sheets (B). According to EDX elemental analysis, the average $\mathrm{Si} / \mathrm{Al}$ ratio in the geopolymeric gel is 2.1 , while the respective ratio in the partially transformed metakaolin was lower $(\mathrm{Si} / \mathrm{Al} \sim 1.8)$. The SEM image reveals that due to geopolymeric reactions the gaps between partially reacted metakaolin sheets have been filled with the formed of sodium aluminosilicate. This finding

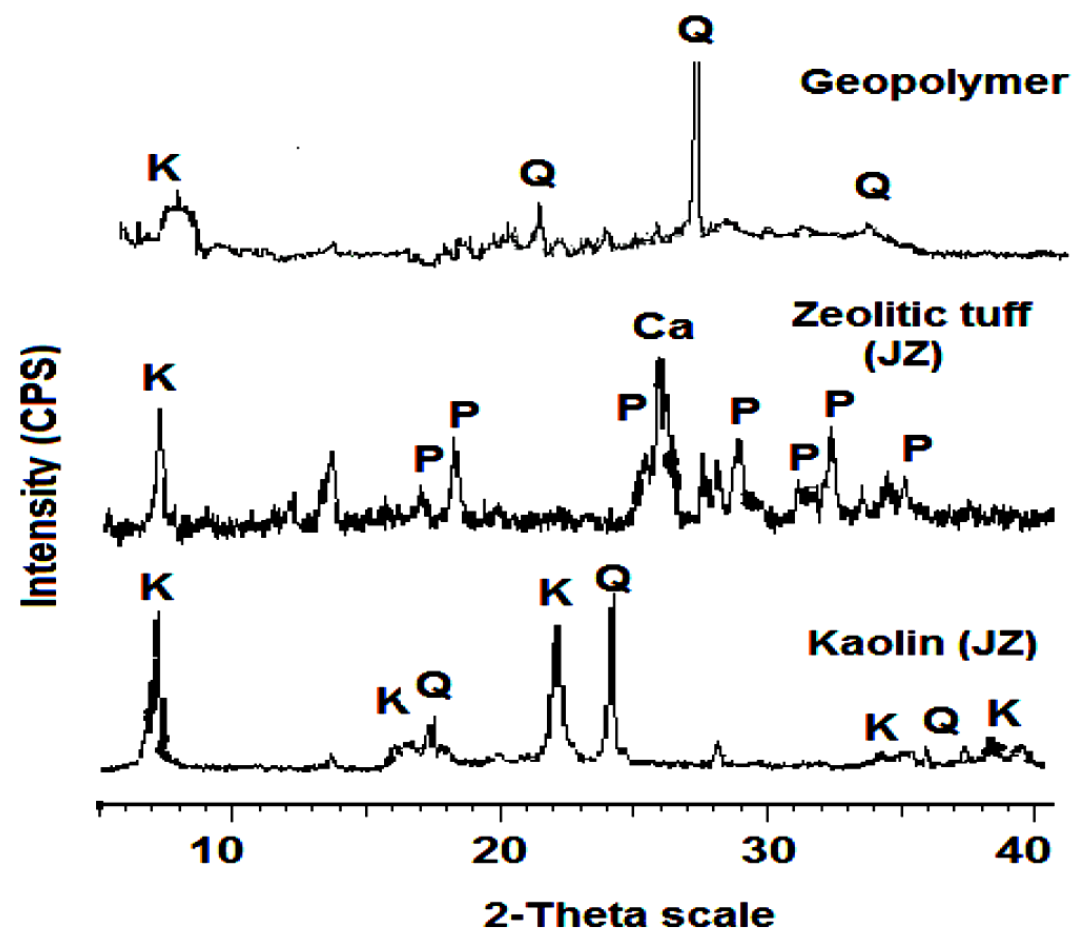

Figure 1. XRD patterns (qualitatively) of powdered kaolin (JK), zeolitic tuff (JZ), and geopolymers (K: kaolinite $\mathrm{Al}_{2} \mathrm{Si}_{2} \mathrm{O}_{5}(\mathrm{OH})_{4}$, Q: quartz $\mathrm{SiO}_{2}$, Ca: calcite $\mathrm{CaCO}_{3}$, P: phillipsite $\left.\mathrm{K}_{6} \cdot \mathrm{Al}_{6} \mathrm{Si}_{10} \mathrm{O}_{32} \cdot 12 \mathrm{H}_{2} \mathrm{O}\right)$.

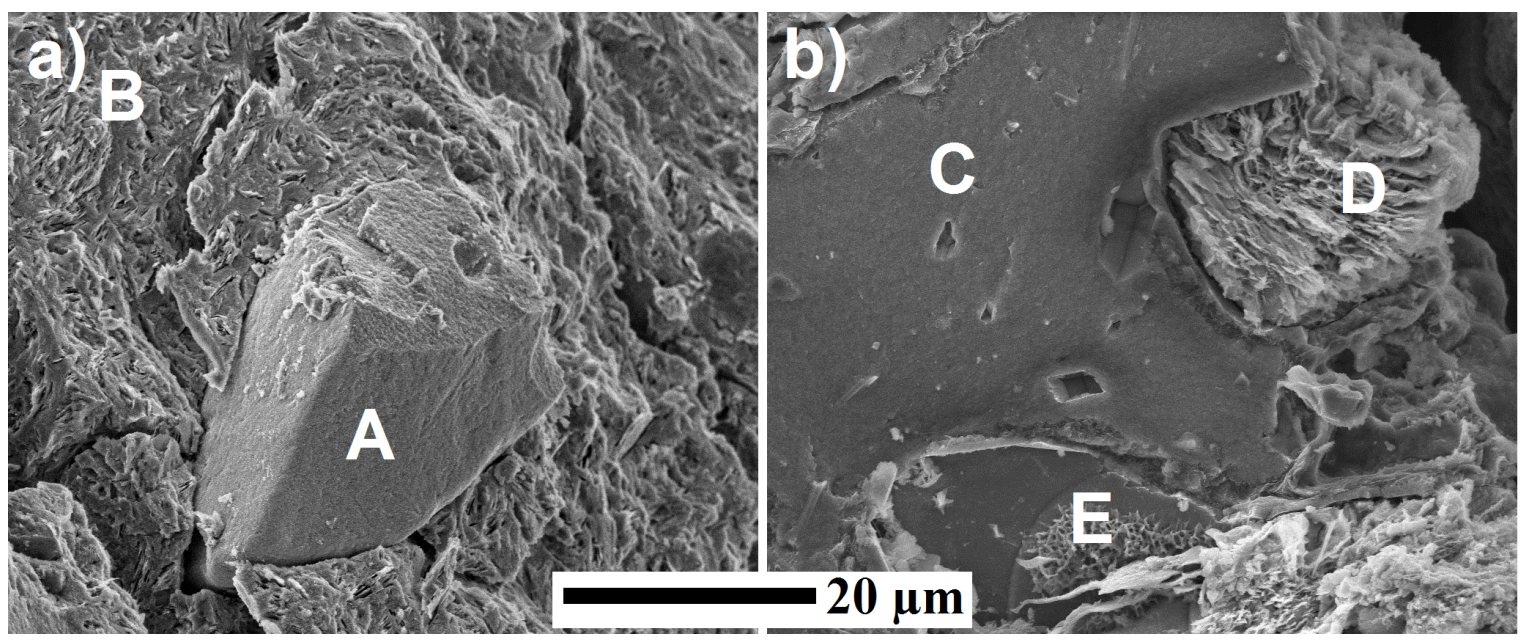

Figure 2. SEM image of 1 geopolymers. 
coincides with the results published by Rahier et al. [14], who obtained partially amorphous sodium aluminosilicates after activation of metakaolin with sodium silicate-activated.

The size of the aluminosilicate particles $(\sim 40 \mathrm{~nm})$ encapsulated in a geopolymer gel determines the pore parameters observed in the microstructure of the formed products. An array of larger particles results in larger pore area and mean pore diameter. The opposite is seen for a gel network consisting of smaller particles. The formation of a uniform pore structure in aluminosilicate particles through sol-gel chemistry is also commonly observed [15]. The particle size can then be easily modified by changing the reaction temperature, curing time, and silicate ratio, as has also been observed in metakaolin-based geopolymer gels..

The precursor (zeolitic tuff) was attacked by the alkaline solution during geoplymerisation as shown in Figure 2(A), Figure 2(C) and Figure 2(D), and was partially consumed. Its residual was amorphous, as seen in Figure 2(B) Figure 2(C). Due to the alkaline attack, macro holes filled with new formed Na-alu-minosilicates products are widely scattered in the residual zeolitic tuff aggregate (B). Intensive silica zones (E) were observed in Figure 2(B). These Silica rich zones, as shown by the EDX, seem to consist of quartz as shown by the XRD patterns in Figure 1. Upon geopolymerization, crystals growth can be observed in Figure 2(B) Figure 2(C). Figure 2(B) shows the formation of new microcrystalline (E) phases formed on the surface of the amorphous residual zeolitic tuff.

Mechanical properties of geopolymers: The tensile bending strength and the compressive strength of the geoplymers are 7.8 MPa and $45 \mathrm{MPa}$, respectively as shown in Figure 3. These strength values are comparable with metakaolin-based geopolymers [4]. The participation of JZ in geopolymerization reactions, and the formation of new binding mineral matrix could have influence on improving the mechanical performance of the final geopolymeric products [10] [12]. Usually the improvement in mechanical properties correlated with the increase in the volume of geopolymeric gel at a relatively constant nominal density, results in a more homogenous microstructure. The evidence presented here shows that strength and microstructure of geopolymeric materials are altered partially by adding zeolitic tuff as reactive material. It was reported [16] that there is an increase in the compressive strength of geopolymers formed from metakaolin by addition of silica to sodium-based alkali activating solution. The potential Si source in this study is the zoelitic tuff, which dissolves in alkaline solution as shown in Figure 1. However, other factors such as the change in liquid/powder ratio and the grain packing of the geopolymer mixture could influence the mechanical properties of the geopolymers.

Adsorption efficiency of geopolymers: The adsorption efficiency of geopolymers discs was investigated in terms of adsorption of $\mathrm{Cu}^{2+}$ ions from a copper solution containing $250 \mathrm{mg} / \mathrm{L} \mathrm{Cu}$. Geopolymeric discs showed significant adsorption rates reaching $9.3 \mathrm{mg} \mathrm{Cu} / \mathrm{g}$. This value is comparable with that of a powdered zeolitic tuff used in a previous work (zeolitic tuff $8.5 \mathrm{mg} / \mathrm{g}, \mathrm{pH} 4$ ) [11]. Although the $\mathrm{pH}$ was adjusted at 3, in which the adsorption capacity of the zeolites is very low [17] compared with neutral conditions, the adsorption of the MZ-geopolymers is still relatively high. This is evident that these geopolymers can be used for adsorption of heavy metals ions even under extreme acidic conditions.

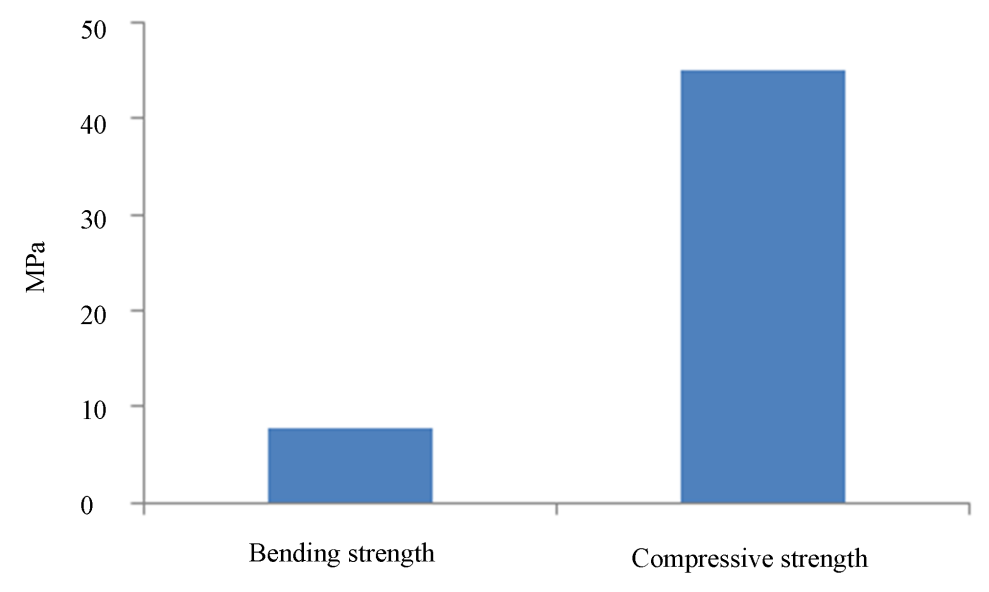

Figure 3. Compressive strength and tensile-bending strength of the geopolymers. 
It was found that the produced geopolymer from low purity metakaolin and natural zeolitic tuff exhibits high removal efficiency of $\mathrm{Cu}(\mathrm{II})$ when compared with other minerals [11]. The formation of nano-porous mineralmatrix upon the geopolymerization increases the efficiency of the adsorption capacity. Zeolite has different sites available for adsorption of heavy metal ions and also has a cage-like structure suitable for ion exchange [18]. However, the adsorption of metal ions onto zeolite particles is a complex process because of their porous structure, inner and outer charged surfaces, mineralogical heterogeneity, crystal edges, and other imperfections on the surface [19] [20]. The incorporation of zeolite with metakaolin revealed that the produced geopolymers show a high adsorption capacity. The XRD pattern of geopolymers showed that all the phillipsite peaks of zeolitic tuff were disappeared upon geopolymerization (Figure 1). Thus, geopolymerization destructs crystals of zeolite leading to more open amorphous structure (Figure 2(a)) which leads to an increase of the number of adsorption sites. The adsorption mechanism of $\mathrm{Cu}^{2+}$ can be proposed as cation exchange of $\mathrm{Na}^{+}$with $\mathrm{Cu}^{2+}$. This is justified as the geopolymerization process was made under highly alkaline solution of $\mathrm{NaOH}$, the dispersion of aluminosilicate particles is due to $\mathrm{Na}^{+}$exchange with the hydrogen ions of the broken edges of aluminosilicate, and the $\mathrm{Na}$ ions play an important role in electrical neutralization of the resultant geopolymeric matrix.

\section{Conclusion}

Metakaolin-Zeolitic tuff geopolymer produced from Jordanian resources has been successfully synthesized by alkali-activation. The product comprised amorphous phases and quartz as revealed by XRD analysis. This study clearly shows the influence of zeolitic tuff on the microstructure, strength and adsorption behavior of geopolymers. The results of the conducted experiment showed that this type of geopolymers exhibits high mechanical performance and high adsorption capacity toward micropollutants and cost effective. The microstructural observations using SEM reveal that the geopolymer consists of a nano-particle matrix with nanosized pore characteristics.

\section{References}

[1] Alshaaer, M., El-Eswed, B., Yousef, R.I., Khalili, F. and Rahier, H. (2012) Development of Functional Geopolymers for Water Purification, and Construction Purposes. Journal of Saudi Chemical Society, in press. http://dx.doi.org/10.1016/j.jscs.2012.09.012

[2] Davidovits, J. (1982) Mineral Polymers and Methods of Making Them. US Patent No 44721993.

[3] Zaharaki, D., Komnitsas, K. and Perdikatsis, V. (2010) Use of Analytical Techniques for Identification of Inorganic Polymer Gel Composition. Journal of Materials Science, 45, 2715-2724. http://dx.doi.org/10.1007/s10853-010-4257-2

[4] Rowles, M. and O'Connor, B. (2003) Chemical Optimisation of the Compressive Strength of Aluminosilicate Geopolymers Synthesized by Sodium Silicate Activation of Metakaolinite. Journal of Materials Chemistry, 13, 1161-1165. http://dx.doi.org/10.1039/b212629j

[5] Davidovits, J. (1999) Chemistry of Geopolymeric Systems Terminology. Proceedings of Geopolymer. International Conference, France, 1999.

[6] Komnitsas, K. and. Zaharaki, D. (2007) Geopolymerisation: A Review and Prospects for the Minerals Industry. Minerals Engineering, 20, 1261-1277. http://dx.doi.org/10.1016/j.mineng.2007.07.011

[7] Li, L., Wang, S. and Zhu, Z. (2006) Geopolymeric Adsorbents from Fly Ash for Dye Removal from Aqueous Solution. Journal of Colloid and Interface Science, 300, 52-59. http://dx.doi.org/10.1016/j.jcis.2006.03.062

[8] Wang, S., Li, L. and Zhu, Z.H. (2007) Solid-State Conversion of Fly Ash to Effective Adsorbents for Cu Removal from Wastewater. Journal of Hazardous Materials, 139, 254-259. http://dx.doi.org/10.1016/j.jhazmat.2006.06.018

[9] Abderahman, N. and Abu-Rukah, Y.H. (2006) An Assessment Study of Heavy Metal Distribution within Soil in Upper Course of Zarqa River Basin/Jordan. Environmental Geology, 49, 1116-1124. http://dx.doi.org/10.1007/s00254-005-0154-4

[10] Alshaaer, M., El-Eswed, B., Yousef, R.I., Khalili, F. and Khoury, H. (2009) Low-Cost Solid Geopolymeric Material for Water Purification. Environmental Issues and Waste Management Technologies in the Materials and Nuclear Industries XII: Ceramic Transactions, published by Wiley, Volume 207.

[11] Yousef, R., El-Eswed, B., Alshaaer, M., Khalili, F. and Khoury, H. (2009) The Influence of Using Jordanian Natural Zeolite on the Adsorption, Physical, and Mechanical Properties of Geopolymers Products. Journal of Hazardous Materials, 165, 379-387. http://dx.doi.org/10.1016/j.jhazmat.2008.10.004

[12] El-Eswed, B., Yousef, R.I., Alshaaer, M., Khalili, F. and Khoury, H. (2009) Alkali Solid-State Conversion of Kaolin 
and Zeolite to Effective Adsorbents for Removal of Lead from Aqueous Solution. Desalination and Water Treatment, 8, 124-130.

[13] Alshaaer, M., Cuypers, H., Rahier, H. and Wastiels, J. (2011) Evaluation of a Low Temperature Hardening Inorganic Phosphate Cement for Construction and Industrial Applications. Cement and Concrete Research, 41, 38-45. http://dx.doi.org/10.1016/j.cemconres.2010.09.003

[14] Rahier, H., Simons, W., Biesemans, M. and Van Mele, B. (1997) Low-Temperature Synthesised Aluminosilicate Glasses: Part III Influence of the Composition of the Silicate Solution on Production, Structure and Properties. Journal of Materials Science, 32, 2237-2247. http://dx.doi.org/10.1023/A:1018563914630

[15] Setzer, C., van Essche, G. and Pryor, N. (2002) title of the article. In: Schuth, F., Sing, K.S.W. and Weitkamp, J., Eds., Handbook of Porous Solids, Vol. 3, Wiley-VCH, Weinheim, 1543.

[16] Duxson, P., Mallicoat, S.W., Lukey, G.C., Kriven, W.M. and van Deventer, J.S.J. (2007) The Effect of Alkali and $\mathrm{Si} / \mathrm{Al}$ Ratio on the Development of Mechanical Properties of Metakaolin-Based Geopolymers. Colloids and Surfaces A: Physicochemical and Engineering Aspects, 292, 8-20. http://dx.doi.org/10.1016/j.colsurfa.2006.05.044

[17] Cheng, T.W., Lee, M.L., Ko, M.S., Ueng, T.H. and Yang, S.F. (2012) The Heavy Metal Adsorption Characteristics on Metakaolin-Based Geopolymer. Applied Clay Science, 56, 90-96. http://dx.doi.org/10.1016/j.clay.2011.11.027

[18] Peric, J., Trgo, M. and Medvidovic, N.V. (2004) Removal of Zinc, Copper and Lead by Natural Zeolite-A Comparison of Adsorption Isotherms. Water Research, 38, 1893-1899. http://dx.doi.org/10.1016/j.watres.2003.12.035

[19] Baerlocher, C., Meier, W.M. and Olson, D.H. (2001) Atlas of Zeolite Structure Types. 5th Edition, Elsevier, London. http://www.iza-structure.org

[20] Schreier, M., Teren, S., Belcher, L., Regalbuto, J.R. and Miller, J.T. (2005) The Nature of 'Over Exchanged' Copper and Platinum on Zeolites. Nanotechnology, 16, 582-591. http://dx.doi.org/10.1088/0957-4484/16/7/036 